\title{
Simple and sensitive liquid chromatography-tandem mass spectrometry methods for quantification of paraquat in plasma and urine: Application to experimental and clinical toxicological studies
}

\author{
Klintean Wunnapuk ${ }^{\mathrm{a}, \mathrm{b}}$, Gregory A. Medley ${ }^{\mathrm{a}}$, Xin Liu ${ }^{\mathrm{a}}$, Jeffrey E. Grice ${ }^{\mathrm{a}}$, Sudheera Jayasinghe ${ }^{\mathrm{c}, \mathrm{d}}$, \\ Indika Gawarammana $^{\mathrm{d}, \mathrm{e}, \mathrm{f}}$, Nicholas A. Buckley ${ }^{\mathrm{e}, \mathrm{f}, \mathrm{g}}$, Michael S. Roberts ${ }^{\mathrm{a}, \mathrm{h}, *}$ \\ a Therapeutics Research Centre, School of Medicine, University of Queensland, Brisbane, QLD, Australia \\ ${ }^{\mathrm{b}}$ Department of Forensic Medicine, Faculty of Medicine, Chiang Mai University, Chiang Mai, Thailand \\ ${ }^{c}$ Department of Pharmacology, Faculty of Medicine, University of Ruhuna, Sri Lanka \\ d Department of Medicine, Faculty of Medicine, University of Peradeniya, Sri Lanka \\ e Australian National University, Canberra, Australia \\ ${ }^{\mathrm{f}}$ South Asian Clinical Toxicology Research Collaboration, Faculty of Medicine, University of Peradeniya, Sri Lanka \\ g Professorial Medicine Unit, University of New South Wales, NSW, Australia \\ h School of Pharmacy and Medical Science, University of South Australia, Adelaide, SA, Australia
}

\section{A R T I C L E I N F O}

\section{Article history:}

Received 21 June 2011

Accepted 4 September 2011

Available online 10 September 2011

\section{Keywords:}

Paraquat

Herbicide

LC-MS/MS

HILIC column

\begin{abstract}
A B S T R A C T
Simple, sensitive and specific liquid chromatography-tandem mass spectrometry (LC-MS/MS) methods have been developed and validated for quantification of paraquat (PQ) in plasma and urine. Plasma and urine sample preparation were carried out by one-step protein precipitation using cold acetonitrile $\left(-20\right.$ to $\left.-10^{\circ} \mathrm{C}\right)$. After centrifugation, an aliquot of $10 \mu \mathrm{L}$ of supernatant was injected into a Kinetex ${ }^{\mathrm{TM}}$ hydrophilic interaction chromatography (HILIC) column with a KrudKatcher ${ }^{\mathrm{TM}}$ Ultra in-line filter. The chromatographic separation was achieved using the mobile phase mixture of $250 \mathrm{mM}$ ammonium formate (with $0.8 \%$ aqueous formic acid) in water and acetonitrile at a flow rate of $0.3 \mathrm{~mL} / \mathrm{min}$. Detection was performed using an API2000 triple quadrupole tandem mass spectrometer in multiple reaction monitoring (MRM) mode via an electrospray ionization (ESI) source. The calibration curve was linear over the concentration range of $10-5000 \mathrm{ng} / \mathrm{mL}$, with an LLOQ of $10 \mathrm{ng} / \mathrm{mL}$. The inter- and intra-day precision (\% R.S.D.) were $<8.5 \%$ and $6.4 \%$ for plasma and urine, respectively with the accuracies (\%) within the range of $95.1-102.8 \%$. PQ in plasma and urine samples was stable when stored at $-70^{\circ} \mathrm{C}$ for three freeze-thaw cycles. The methods were successfully applied to determine PQ concentration in rat and human samples.
\end{abstract}

(c) 2011 Elsevier B.V. All rights reserved.

\section{Introduction}

Paraquat (1,1'-dimethyl-4,4'-bipyridylim dichloride, also known as methyl viologen) (PQ) is a globally used herbicide with a broad spectrum of activity $[1,2]$. PQ is a quaternary ammonium herbicide which is highly soluble in water (Fig. 1) [3]. Concentrated PQ contains an aliphatic detergent which enhances its permeability into cells and toxicities [2]. In general, PQ solutions are neutral; however, they can be irritant and corrosive [2]. Toxic effects of PQ can occur in multiple organs [2]. Acute renal failure is the first systemic symptom observed in PQ toxicity although

\footnotetext{
* Corresponding author at: Therapeutics Research Centre, School of Medicine, The University of Queensland, Princess Alexandra Hospital, Woolloongabba, QLD 4102, Australia. Tel.: +61 7 31762546; fax: +61 731765806 .

E-mail address: m.roberts@uq.edu.au (M.S. Roberts).
}

the main cause of death from PQ toxicity is severe pulmonary damage [2,4-7]. Mortality rate from accidental or intentional paraquat ingestion has been reported to be high especially in Asia [8-10]. An analytical method for plasma and urine is essential for toxicokinetic studies of this herbicide. In addition, measuring plasma and urine concentrations of $\mathrm{PQ}$ can allow prediction of patient outcomes following PQ intoxication. Recently, PQ plasma and urine levels have been successfully used to predict survival or death using a nomogram method [10].

Liquid chromatography-tandem mass spectrometry (LC-MS/MS) has been recommended as a sensitive and selective technique for $\mathrm{PQ}$ analysis in a broad range of specimens [3,11-16]. LC-MS/MS with electrospray ionization (ESI) has become the method of choice for PQ analysis due to PQ being a doubly charged cationic species in solution $[16,17]$. Many different procedures have been used for PQ extraction from biological samples, including liquid-liquid extraction (LLE) [18] and solid-phase 
paraquat $(P Q)$<smiles>C[n+]1ccc(-c2cc[n+](C)cc2)cc1</smiles><smiles>C[n+]1ccc(-c2ccncc2)cc1</smiles>

ethyl viologen (EV)

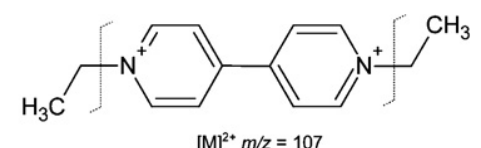

$[\mathrm{M}]^{2+} \mathrm{m} / \mathrm{z}=107$

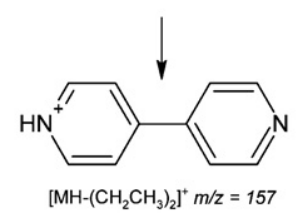

Fig. 1. Chemical structure of paraquat and ethyl viologen and their fragment ions.

extraction (SPE) $[3,14,19]$. Disadvantages of LLE include low recovery and lengthy procedures [3]. While cation exchangers $[3,11,16]$ and silica $C_{18}$ Sep-Paks $[14,19]$ have been successfully used for solid phase extraction of $\mathrm{PQ}$, they are impractical for high sample numbers as they are time consuming and costly.

Recently, ion-pair reagents, such as trifluoroacetic acid (TFA), tetrabutylammonium hydroxide (TBAOH) and heptafluorobutyric acid (HFBA), have been used with reverse-phase silica-based $C_{8}$ or $\mathrm{C}_{18}$ columns to separate the highly polar PQ in biological samples $[3,11-14,20]$. The addition of salts like ammonium acetate to the mobile phase containing the ion-pair reagents has also been shown to improve the separation and resolution of PQ $[3,13,16]$. Nevertheless, in the presence of ion-pair reagents, the sensitivity of the methods decreases due to ion suppression $[15,16]$.

The HILIC column is an alternative approach to the separation of highly polar compounds [21]. Typical HILIC stationary phases are bare silica and silica embedded with different polar functional groups including amine, cyano and diol [22]. An interaction of polar moieties such as hydroxyl groups in the analytes with the stationary phase, as well as with the organic and aqueous mobile phase has been suggested as a retention mechanism [21,23]. The HILIC column allows the separation of hydrophilic compounds on polar stationary phases [24] and has been previously used for the analysis of PQ analysis in urine, following SPE under isocratic LC conditions [16].

In this work, we developed an efficient and simple method for determining PQ in rat and human samples by LC-MS/MS. The sample preparation was simple, employing only a one-step acetonitrile extraction. The analytical separation using the HILIC silica column was sensitive and precise without the use of ion-pair reagents.

\section{Materials and methods}

\subsection{Materials and reagents}

Paraquat dichloride hydrate (PQ) and ethyl viologen dibromide (EV) were both purchased from Sigma-Aldrich (St. Louis, MO, USA). Acetonitrile and formic acid were mass spectroscopy grade and were obtained from Merck (Kilsyth, VIC, Australia) and Sigma-Aldrich (St. Louis, MO, USA), respectively.

\subsection{Equipment}

The LC-MS/MS system consisted of an SLC-10AVP system controller, two LC-10AD pumps, an SIL-20AC-HT autosampler (Shimadzu, Kyoto, Japan) and an API2000 triple quadrupole (Applied Biosystems Inc., Foster City, CA, USA) mass spectrometer coupled with an electrospray ionization (ESI) source and a divert valve.

\subsection{Chromatographic and mass spectrometric conditions}

\subsubsection{Chromatographic conditions}

The chromatographic separation was modified from Whitehead et al. [16]. Separation was achieved using a Kinetex ${ }^{\mathrm{TM}} 2.6 \mu \mathrm{m}$ HILIC column $(50 \mathrm{~mm} \times 2.10 \mathrm{~mm}$, ID, Phenomenex, Torrance, USA) coupled with KrudKatcher ${ }^{\mathrm{TM}}$ Ultra in-line filter. The mobile phase was a mixture of solvent A ( $250 \mathrm{mM}$ ammonium formate containing $0.8 \%$ formic acid in water) and solvent $B$ (acetonitrile) and was delivered with a gradient at a flow rate of $0.3 \mathrm{~mL} / \mathrm{min}$. The gradient programme commenced at $60(\% \mathrm{~B})$, followed by direct switch to $20(\% \mathrm{~B})$ at $0.1 \mathrm{~min}$, maintained for $3.5 \mathrm{~min}$ for plasma and $5 \mathrm{~min}$ for urine, followed by a direct switch back to $60(\% \mathrm{~B})$ at $3.6 \mathrm{~min}$ for plasma and $5.1 \mathrm{~min}$ for urine and equilibrium for another 4 (for plasma) or $5 \mathrm{~min}$ (for urine) before stopping the run. The total chromatographic analysis time for plasma and urine were 7 and 10 min per sample. The eluents for the first $2 \mathrm{~min}$ and the last 5.5 (for plasma) and $7 \mathrm{~min}$ (for urine) were diverted to waste via the valve.

\subsubsection{Mass spectrometric conditions}

Detection was performed with electrospray ionization operating in positive ion mode and the tandem spectrometer was operated in the multiple reactions monitoring (MRM) mode. The mass spectra for PQ and EV were first obtained in a full scan (Q1 scan) mode by infusion of each compound $(1 \mu \mathrm{g} / \mathrm{mL})$ at $10 \mu \mathrm{L} / \mathrm{min}$. From these spectra, the precursor ions were selected and subjected to product ion scan. The dominant product ions were selected and the most abundant precursor/product ion pair was chosen for MRM. The dwell times were set at $400 \mathrm{~ms}$ for PQ and $100 \mathrm{~ms}$ for EV. Conditions for mass spectrometric detection were as follows: nebulizer gas, 70 psi; turbo gas, 70 psi; curtain gas, 20 psi; focusing potential, $370 \mathrm{~V}$; ion spray voltage, $5000 \mathrm{~V}$; collision gas, 2 ; collision cell entrance potential, $19 \mathrm{~V}$; collision energy, $20 \mathrm{~V}$; declustering potential, $70 \mathrm{~V}$ for PQ and $60 \mathrm{~V}$ for EV; entrance potential, 9.5 V for PQ and $10 \mathrm{~V}$ for $\mathrm{EV}$; collision cell exit potential, $32 \mathrm{~V}$ for $\mathrm{PQ}$ and $15 \mathrm{~V}$ for $\mathrm{EV}$.

\subsection{Preparation of standards and quality control (QC) samples}

The stock solutions of PQ and EV were prepared by weighing out approximately $2.5 \mathrm{mg}$ of each compound in $25 \mathrm{~mL}$ of deionised water. A $20 \mu \mathrm{g} / \mathrm{mL}$ PQ working solution was prepared by diluting $5 \mathrm{~mL}$ of the stock solution with $20 \mathrm{~mL}$ of water. The internal standard working solution $(10 \mu \mathrm{g} / \mathrm{mL}$ of $\mathrm{EV})$ was prepared by 10 times dilution of the stock solution with water. The working standard solutions were stored at $4{ }^{\circ} \mathrm{C}$.

Nine PQ calibration standards were made by adding the working solutions to blank human plasma and urine covering a range from 10 to $5000 \mathrm{ng} / \mathrm{mL}(10,20,50,100,200,500,1000,2000$ and 5000). QC samples at three concentration levels $(30,600$ and $1500 \mathrm{ng} / \mathrm{mL})$ were prepared in the same way.

\subsection{Sample preparation}

Two hundred microliters of cold acetonitrile $\left(-20\right.$ to $\left.-10^{\circ} \mathrm{C}\right)$ were added to $100 \mu \mathrm{L}$ of plasma or urine and mixed with $10 \mu \mathrm{L}$ of internal standard $(E V, 10 \mu \mathrm{g} / \mathrm{mL})$. The mixture was vortexed for $10 \mathrm{~s}$ and centrifuged at $14,500 \mathrm{rpm}$ for $15 \mathrm{~min}$. The supernatant was then transferred to an HPLC vial and $10 \mu \mathrm{L}$ of the sample was injected into the LC-MS/MS system.

\subsection{Method validation}

\subsubsection{Linearity and lower limit of quantification (LLOQ)}

The linearity of the method was determined by analysing calibration standards ranging from 10 to $5000 \mathrm{ng} / \mathrm{mL}$. The calibration curve was constructed using a weighted $\left(1 / \chi^{2}\right)$ linear least-squares 
Table 1

Mass spectra obtained by LC-MS/MS.

\begin{tabular}{|c|c|c|c|c|}
\hline Compound & Molecular weight & Precursor ion $m / z$ (relative intensity (\%)) & Assignment & Product ion $m / z$ (relative intensity (\%)) \\
\hline \multirow{3}{*}{ PQ } & \multirow{3}{*}{186} & $186(22)$ & {$[\mathrm{M}]^{+}$} & $186(11), 171(100)$ \\
\hline & & $185(22)$ & {$[\mathrm{M}-\mathrm{H}]^{+}$} & 185 (100), 170 (39), 169 (85), 158 (39), 144 (50) \\
\hline & & $93^{\mathrm{a}}(100)$ & {$[\mathrm{M}]^{2+}$} & $171^{\mathrm{a}}(100), 169(25), 142(29), 93(12)$ \\
\hline \multirow{4}{*}{ EV } & \multirow{4}{*}{214} & $214(9)$ & {$[\mathrm{M}]^{+}$} & $185(100), 213(62)$ \\
\hline & & $213(23)$ & {$[\mathrm{M}-\mathrm{H}]^{+}$} & 185 (100), 213 (68) \\
\hline & & $185(45)$ & {$\left[\mathrm{M}-\mathrm{C}_{2} \mathrm{H}_{5}\right]^{+}$} & $185(63), 157(100)$ \\
\hline & & $107^{\mathrm{a}}(100)$ & {$[\mathrm{M}]^{2+}$} & $184(17), 157^{\mathrm{a}}(100), 130(17)$ \\
\hline
\end{tabular}

${ }^{\text {a }}$ Ion selected for quantitation.

regression of the peak area ratios of $\mathrm{PQ}$ to EV obtained against the corresponding concentrations. The LLOQ was defined as the lowest concentration in the calibration curve based on visual evaluation at which the analyte can be reliably detected with acceptable precision and accuracy $[25,26]$.

\subsubsection{Matrix effect}

Six batches of blank plasma and urine were screened for possible endogenous interferences. Matrix effects were evaluated by analysing responses of $\mathrm{PQ}$ solution spiked into six different batches of blank human plasma and urine at low $(20 \mathrm{ng} / \mathrm{mL})$ and high $(2000 \mathrm{ng} / \mathrm{mL})$ concentrations. The PQ concentrations detected in 6 different batches were compared to those of the nominal concentrations, and the matrix effect was reported as the percentage values.

\subsubsection{Accuracy and precision}

The intra-day accuracy and precision were evaluated by analysing eight replicates of QC samples at three concentration levels, in a single run. In order to determine inter-day accuracy and precision, five replicates of QC samples were analysed on five different validation days. Precision was represented by the percentage of relative standard deviations (\%R.S.D) while accuracy was expressed as (mean concentration)/(spiked concentration) $\times 100 \%$. The acceptable tolerance for precision and accuracy was within 15\% except at LLOQ, where it should not exceed $20 \%[25,26]$.

\subsubsection{Stability test}

The stability of the analyte in the matrix was determined by monitoring the degradation of samples when exposed to arbitrary conditions of storage and handling. It was tested after three freeze/thaw cycles with eight replicates of QC samples at 30, 600 and $1500 \mathrm{ng} / \mathrm{mL}$ in both plasma and urine. The samples were stored at $-70^{\circ} \mathrm{C}$ between freeze/thaw cycles, and were thawed by allowing them to stand at room temperature for approximately $30 \mathrm{~min}$. The QC samples were also analysed one month after preparation to determine the long-term storage stability. Short-term stability in the matrix during $3 \mathrm{~h}$ at ambient laboratory temperature $\left(24 \pm 3^{\circ} \mathrm{C}\right)$ was also determined. The post-preparative stability was determined by injection of prepared samples (kept at $4{ }^{\circ} \mathrm{C}$ ) for 4 or 5 days after the initial injection.

\subsection{Application to animal and human toxicological studies}

\subsubsection{Animal study}

Male Wistar rats (200-250 g) received PQ orally at 3 different doses $(15,30$ and $60 \mathrm{mg} / \mathrm{kg}$ ), with one rat per dose group. Blood samples were collected at $24 \mathrm{~h}$ and the urine was collected at intervals $0-4,4-8,8-12$ and $12-24 \mathrm{~h}$. The concentrations of $P Q$ in rat plasma and urine samples were determined using the validated methods. The animal experiments were approved by the University Animal Ethics Committee (Health Sciences) of the University of Queensland (AEC approval number: PAH/370/10/NHMRC).

\subsubsection{Human study}

These established methods were applied to analyse 150 plasma samples from patients admitted to hospitals in Sri Lanka with acute PQ toxicity. This study was coordinated by the South Asian Clinical Toxicology Research Collaboration (SACTRC; www.sactrc.org). The human study was approved by the Human Research Ethics Committees of the Australian National University, the University of New South Wales and the Committee on Research and Ethical Review of the Faculty of Medicine, University of Peradeniya.

\section{Results and discussion}

\subsection{Chromatographic and mass spectrometric conditions}

The precursor and product quantification ion pairs obtained by LC-MS/MS are summarized in Table 1 . The most abundant ions of PQ and EV in our mobile phase containing ammonium formate with formic acid are the doubly charged molecular ions $[\mathrm{M}]^{2+}$, at $\mathrm{m} / \mathrm{z}$ 93 and 107, respectively. A multiple reaction monitoring (MRM) mode was used for quantification with the mass transitions from $93[\mathrm{M}]^{2+}$ to $171\left[\mathrm{M}-\mathrm{CH}_{3}\right]^{+}$and $107[\mathrm{M}]^{2+}$ to $157\left[\mathrm{MH}-\left(\mathrm{C}_{2} \mathrm{H}_{5}\right)_{2}\right]^{+}$for $\mathrm{PQ}$ and $\mathrm{EV}$, respectively. MS/MS product ion scan and the proposed fragmentation pathways of PQ are illustrated in Fig. 1.

The liquid chromatography was optimized on a HILIC column under gradient conditions. Good separation and retention of the analyte and the internal standard were achieved in a total run time of 7 and $10 \mathrm{~min}$ in plasma and urine, respectively. For highly polar compounds like $\mathrm{PQ}$, separation on the HILIC column is by partitioning and weak cation exchange [16]. Representative chromatograms of blank plasma and urine samples and spiked samples at LLOQ and $1 \mu \mathrm{g} / \mathrm{mL}$ of PQ are shown in Fig. 2.

Diversion of the early and late eluent to waste reduced the background noise and kept the ion source clean. One step protein precipitation with acetonitrile was suitable for both plasma and urine sample preparation without any effect on separation and ionization.

\subsection{Method validation}

\subsubsection{Linearity of calibration and LLOQ}

The standard curve was linear over a concentration range of $10-5000 \mathrm{ng} / \mathrm{mL}$ in both plasma and urine (Table 2). The relative standard deviation (R.S.D.) values of the retention times for PQ in each matrix were within $2.0 \%$. The linear regression of the ratio of the areas of the analyte and internal standard peaks versus the concentration was weighted by $1 / x^{2}$. The LLOQs were established at $10 \mathrm{ng} / \mathrm{mL}$ of PQ with the accuracy and precision of 109.2 and $5.9 \%$

Table 2

Linearity validation data.

\begin{tabular}{lllll}
\hline Sample & $\begin{array}{l}t_{\mathrm{R}}(\min ) \\
\text { Mean } \pm \mathrm{SD}\end{array}$ & $\begin{array}{l}\text { Linear } \\
\text { regression }\left(R^{2}\right)\end{array}$ & R.S.D. (\%) & Accuracy (\%) \\
\hline Plasma & $3.58 \pm 2.0$ & $0.9947-0.9991$ & $1.9-9.2$ & $92.8-105.6$ \\
Urine & $3.85 \pm 1.4$ & $0.9910-0.9974$ & $2.7-10.1$ & $97.8-106.9$ \\
\hline
\end{tabular}



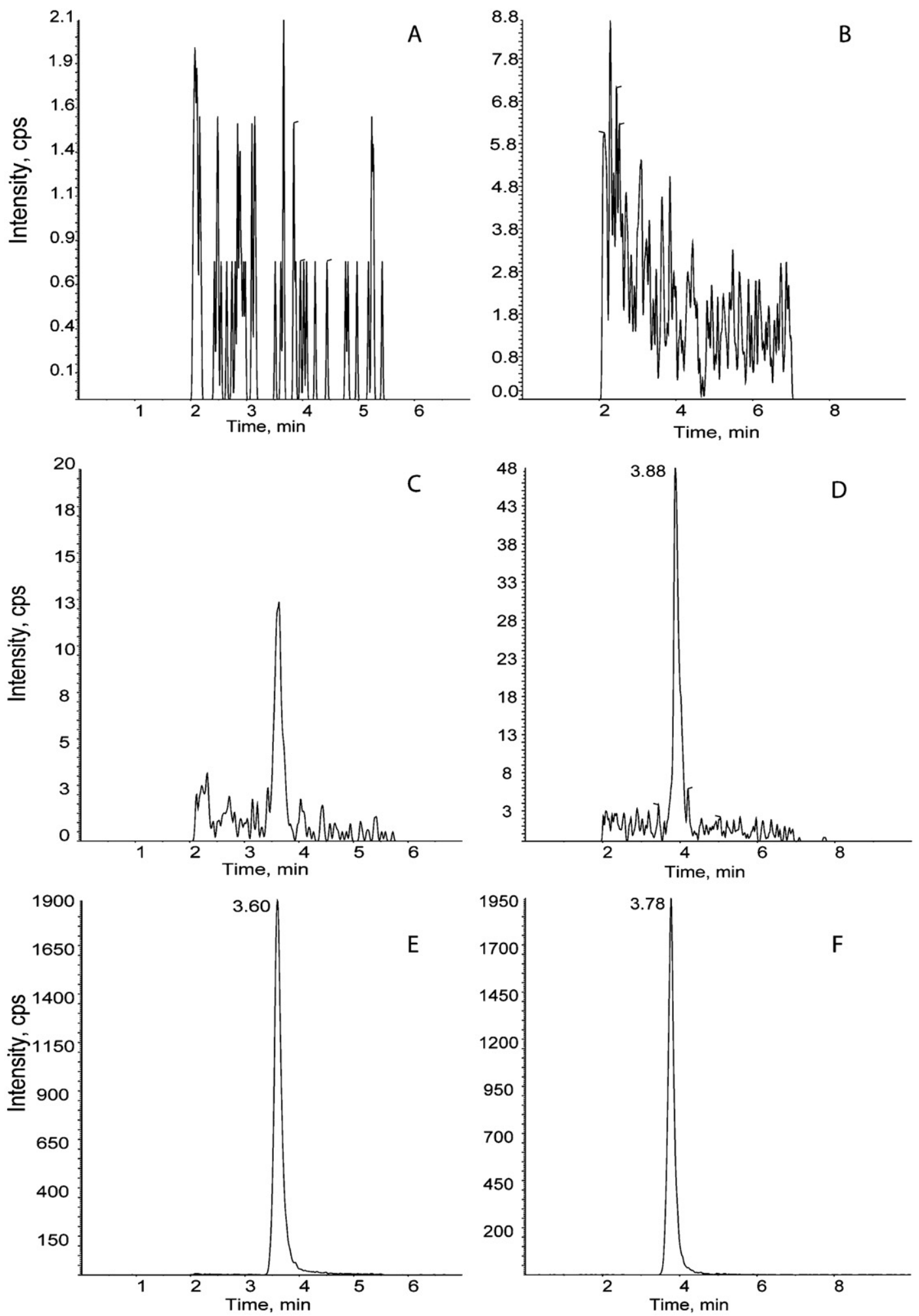

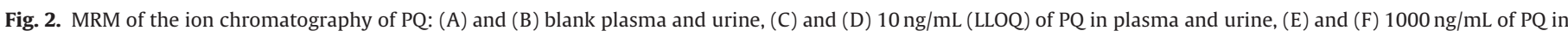
plasma and urine.

and 102.9 and $7.3 \%$ in plasma and urine, respectively. The LLOQ values were comparable to those in previous reports $[11,14]$.

\subsubsection{Matrix effect}

Six batches of urine and plasma samples were spiked with PQ and analysed and the variations due to matrix effects were calculated. As shown in Table 3, there were no significant matrix effects for PQ at low (20 ng/mL) and high (2000 ng/mL) concentrations. The variations (\% R.S.D.) among different matrices were between 4.4 and $9.7 \%$.

\subsubsection{Accuracy and precision}

The intra- and inter-day precision in plasma and urine were within $10 \%$ range and the accuracy of PQ determination in plasma 
Table 3

Matrix effect.

\begin{tabular}{lccc}
\hline Sample & $\begin{array}{l}\text { Nominal concentration } \\
(\mathrm{ng} / \mathrm{mL})\end{array}$ & Matrix effect $(\%)$ & Mean $\pm \mathrm{SD}(\%)$ \\
\hline Plasma & 20 & 107.50 & 103.71 \\
& 2000 & 99.92 & \pm 5.40 \\
Urine & 20 & 105.75 & 105.04 \\
& 2000 & 104.33 & \pm 1.00 \\
\hline
\end{tabular}

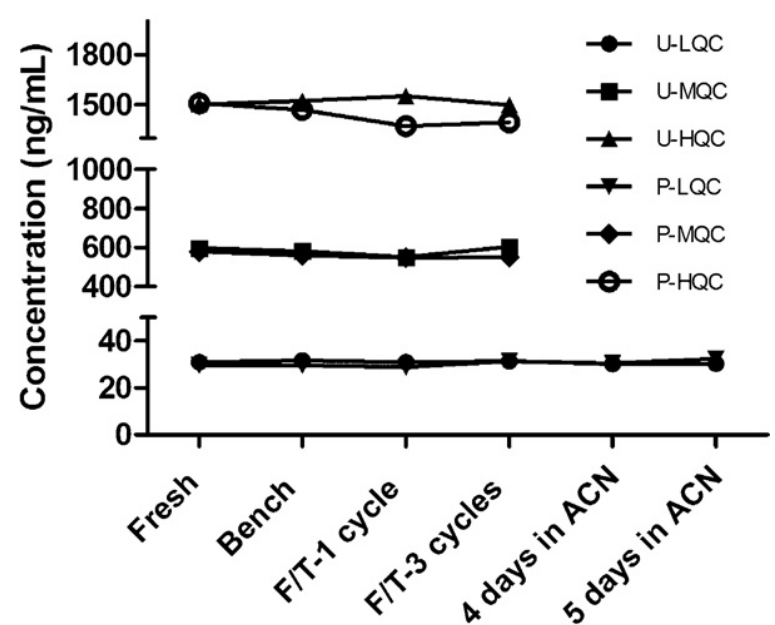

Fig. 3. The stability of $P Q$ in matrices, $U$ : urine, $P$ : plasma, LQC: low level quality control (30 ng/mL), MQC: medium level quality control (600 ng/mL), HQC: high level quality control (1500 ng/mL), F/T: freeze/thaw, ACN: acetonitrile.

and urine were between 95.1 and $103.2 \%$. A summary of the intraday and inter-day precision and accuracy is presented in Table 4.

\subsubsection{Stability test}

The short-term stability of PQ in plasma and urine at ambient temperatures was assessed over at least $3 \mathrm{~h}$ by comparison with the initial measured concentrations, as shown in Fig. 3. The plasma and urine standard samples were stable after storage at $-70^{\circ} \mathrm{C}$ for at least one month. Freeze/thaw stability experiments indicated that PQ was stable in human plasma and urine for at least three freeze/thaw cycles. After preparation, the samples were found to be stable for at least 5 days at $4{ }^{\circ} \mathrm{C}$. The relative deviations of detected concentrations were within $15 \%$ for all levels of QC samples.

\subsection{Application to animal and human specimens}

\subsubsection{Animal samples}

These methods were successfully applied in toxicokinetic studies. PQ was detected and quantified in plasma and urine samples taken at 3 different time points after oral administration. The identity of PQ was confirmed by the retention time and the

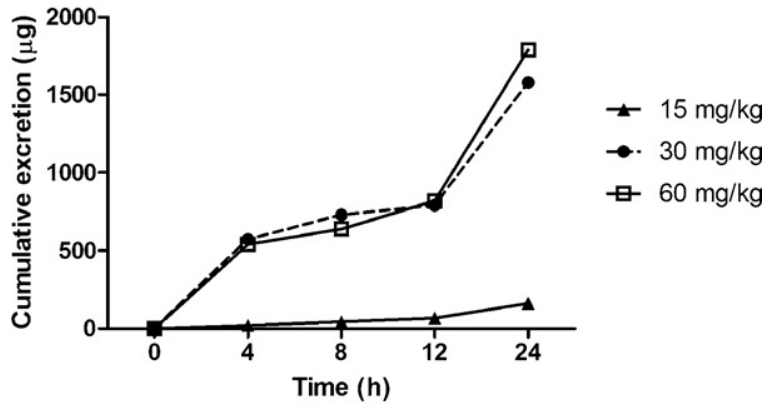

Fig. 4. Cumulative urine excretion of $P Q$ in rats after oral administration of 3 different doses.

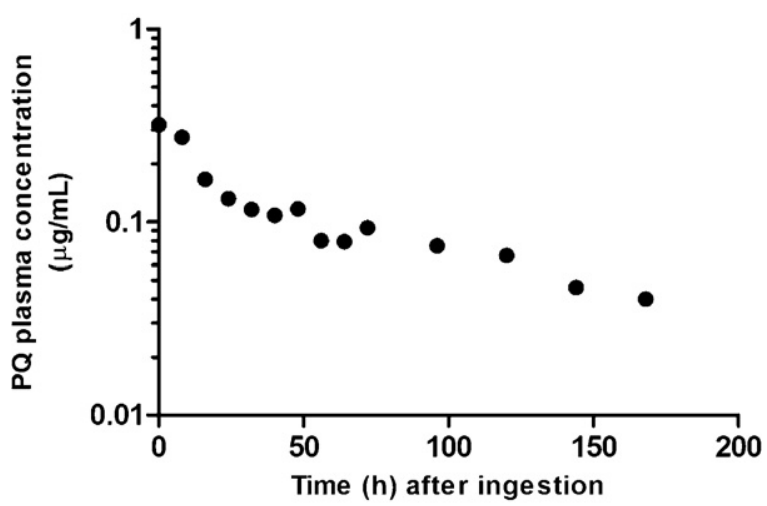

Fig. 5. Plasma concentration-time profile of a representative $P Q$ intoxication patient.

identity of the parent ion $\left([\mathrm{M}]^{2+}\right)$ at $m / z=93$ and the major ionic fragment $\left(\left[\mathrm{M}-\mathrm{CH}_{3}\right]^{+}\right)$at $m / z=171$, as shown in the spectrum of standard $\mathrm{PQ}$. The cumulative excretion curve of $\mathrm{PQ}$ in urine is shown in Fig. 4. The concentrations of $P Q$ in plasma and urine after oral administration ranged from less than $0.01-5135 \mu \mathrm{g} / \mathrm{mL}$ (Table 5).

\subsubsection{Human samples}

The developed method was also used to analyse 150 clinical human plasma samples. The retention time and precursor and product ion spectra of PQ in the sample matched well with those of the authentic standard. Those clinical samples with PQ concentration above the upper limit of quantification $(5000 \mathrm{ng} / \mathrm{ml})$ were reanalysed with a dilution of 10 or 100 times as appropriate with water before sample preparation. Plasma concentrations of PQ varied from less than 0.01 to $461.5 \mu \mathrm{g} / \mathrm{mL}$. A representative plasma concentration-time profile of a PQ intoxication patient is shown in Fig. 5.

Table 4

Intra- and inter-day precision and accuracy for PQ in human plasma and urine.

\begin{tabular}{|c|c|c|c|c|c|c|c|}
\hline \multirow[t]{2}{*}{ Sample } & \multirow{2}{*}{$\begin{array}{l}\text { Nominal concentration } \\
(\mathrm{ng} / \mathrm{mL})\end{array}$} & \multicolumn{3}{|l|}{ Intra-day } & \multicolumn{3}{|l|}{ Inter-day } \\
\hline & & $\begin{array}{l}\text { Mean detected } \\
(\mathrm{ng} / \mathrm{mL})\end{array}$ & R.S.D. (\%) & Accuracy (\%) & $\begin{array}{l}\text { Mean detected } \\
(\mathrm{ng} / \mathrm{mL})\end{array}$ & R.S.D. (\%) & $\overline{\text { Accuracy (\%) }}$ \\
\hline \multirow[t]{3}{*}{ Plasma } & 30 & 29.6 & 8.5 & 98.7 & 29.8 & 3.6 & 99.3 \\
\hline & 600 & 579 & 3.7 & 96.5 & 571 & 2.7 & 95.1 \\
\hline & 1500 & 1509 & 5.2 & 101 & 1472 & 4.4 & 98.1 \\
\hline \multirow[t]{3}{*}{ Urine } & 30 & 40.0 & 5.7 & 103 & 29.8 & 3.1 & 99.5 \\
\hline & 600 & 598 & 1.9 & 99.6 & 585 & 3.8 & 97.6 \\
\hline & 1500 & 1,504 & 2.6 & 100 & 1,542 & 6.4 & 103 \\
\hline
\end{tabular}


Table 5

The concentrations of PQ in plasma and urine after oral administration (rat study).

\begin{tabular}{llrrrr}
\hline \multirow{2}{*}{ Dose $(\mathrm{mg} / \mathrm{kg})$} & Plasma $(\mu \mathrm{g} / \mathrm{mL})$ & \multicolumn{4}{l}{ Urine $(\mu \mathrm{g} / \mathrm{mL})$} \\
\cline { 2 - 6 } & $24 \mathrm{~h}$ & \multicolumn{1}{c}{$4 \mathrm{~h}$} & \multicolumn{1}{c}{$8 \mathrm{~h}$} & $12 \mathrm{~h}$ & $24 \mathrm{~h}$ \\
\hline 15 & 0.01 & 10.03 & 11.75 & 8.10 & 5.25 \\
30 & 0.01 & 287.00 & 52.15 & 30.00 & 3.03 \\
60 & 0.05 & 108.50 & 49.30 & 59.30 & 10.11 \\
\hline
\end{tabular}

\section{Conclusions}

The proposed methods have been successfully applied to quantify PQ in plasma and urine samples. These methods provide accuracy and precision for determination of PQ in animal experiments and acute PQ poisoning cases, are simple to perform and provide sensitivity comparable to previous literature reports. The use of the HILIC column for LC separation of PQ followed by electrospray ionization-tandem mass spectrometry (ESI-MS/MS) with a single step extraction enabled us to accurately quantify PQ in plasma and urine without a solid phase extraction procedure or the use of ion-pair agents.

\section{Acknowledgements}

The authors are grateful to Mrs. Camilla Thomson for her help in animal experimentation. This study was supported by project grants (268053 and 1011772) from the National Health and Medical Research Committee of Australia. KW was supported by Chiang Mai University Scholarship.

\section{References}

[1] E. Bairaktari, K. Katopodis, K.C. Siamopoulos, O. Tsolas, Clin. Chem. 44 (1998) 1256.

[2] R.J. Dinis-Oliveira, J.A. Duarte, A. Sanchez-Navarro, F. Remiao, M.L. Bastos, F. Carvalho, Crit. Rev. Toxicol. 38 (2008) 13.
[3] K.C. Wang, S.M. Chen, J.F. Hsu, S.G. Cheng, C.K. Lee, J. Chromatogr. B Analyt. Technol. Biomed. Life Sci. 876 (2008) 211.

[4] D.A. Purser, M.S. Rose, Toxicology 15 (1979) 31

[5] G.M. Hawksworth, P.N. Bennett, D.S. Davies, Toxicol. Appl. Pharmacol. 57 (1981) 139.

[6] E.A. Lock, J. Ishmael, Toxicol. Appl. Pharmacol. 50 (1979) 67

[7] E.A. Lock, Toxicol. Appl. Pharmacol. 48 (1979) 327.

[8] D.M. Roberts, M.F. Wilks, M.S. Roberts, R. Swaminathan, F. Mohamed, A.H. Dawson, N.A. Buckley, Toxicol. Lett. 202 (2011) 69.

[9] I.B. Gawarammana, N.A. Buckley, Br. J. Clin. Pharmacol. (2011).

[10] L. Senarathna, M. Eddleston, M.F. Wilks, B.H. Woollen, J.A. Tomenson, D.M. Roberts, N.A. Buckley, QJM 102 (2009) 251.

[11] M.M. Ariffin, R.A. Anderson, J. Chromatogr. B Analyt. Technol. Biomed. Life Sci. 842 (2006) 91.

[12] R. Castro, E. Moyano, M.T. Galceran, J. Chromatogr. A 830 (1999) 145.

[13] M. Ito, Y. Hori, M. Fujisawa, A. Oda, S. Katsuyama, Y. Hirose, T. Yoshioka, Biol. Pharm. Bull. 28 (2005) 725.

[14] X.P. Lee, T. Kumazawa, M. Fujishiro, C. Hasegawa, T. Arinobu, H. Seno, A. Ishii, K. Sato, J. Mass Spectrom. 39 (2004) 1147.

[15] C.R. Mallet, Z. Lu, J.R. Mazzeo, Rapid Commun. Mass Spectrom. 18 (2004) 49.

[16] R.D. Whitehead Jr., M.A. Montesano, N.K. Jayatilaka, B. Buckley, B. Winnik, L.L. Needham, D.B. Barr, J. Chromatogr. B Analyt. Technol. Biomed. Life Sci. 878 (2010) 2548

[17] R. Castro, E. Moyano, M.T. Galceran, J. Chromatogr. A 914 (2001) 111.

[18] S.K. Baeck, Y.S. Shin, H.S. Chung, M.Y. Pyo, Arch. Pharm. Res. 30 (2007) 235.

[19] C. Fuke, T. Arao, Y. Morinaga, H. Takaesu, K. Ameno, T. Miyazaki, Leg. Med. (Tokyo) 4 (2002) 156.

[20] B.B. Sadi, A.P. Vonderheide, J.A. Caruso, J. Chromatogr. A 1050 (2004) 95.

[21] V.V. Tolstikov, O. Fiehn, Anal. Biochem. 301 (2002) 298.

[22] Z. Hao, B. Xiao, N. Weng, J. Sep. Sci. 31 (2008) 1449

[23] A.J. Alpert, M. Shukla, A.K. Shukla, L.R. Zieske, S.W. Yuen, M.A. Ferguson, A. Mehlert, M. Pauly, R. Orlando, J. Chromatogr. A 676 (1994) 122.

[24] Y. Guo, S. Gaiki, J. Chromatogr. A 1074 (2005) 71.

[25] FDA, in: http://www.fda.gov/downloads/Drugs/GuidanceCompliance RegulatoryInformation/Guidances/ucm070107.pdf, U.S. Department of Health and Human Services, Food and Drug Administration, 2001.

[26] FDA, in: http://www.fda.gov/downloads/Regulator\%20yInformation/ Guidances/UCM128049.pdf, U.S. Department of Health and Human Services, Food and Drug Administration, 1996. 